\title{
Induction of VEGF secretion from bone marrow stromal cell line (ST-2) by the dissolution products of mesoporous silica glass particles containing $\mathrm{CuO}$ and $\mathrm{SrO}$
}

\author{
Preethi Balasubramanian ${ }^{\mathrm{a}}$, Antonio J. Salinas ${ }^{\mathrm{b}, \mathrm{c}}$, Sandra Sanchez-Salcedo ${ }^{\mathrm{b}, \mathrm{c}}$, Rainer Detsch ${ }^{\mathrm{a}}$, \\ Maria Vallet-Regi ${ }^{\mathrm{b}, \mathrm{c}}$, Aldo R. Boccaccini ${ }^{\mathrm{a}, *}$ \\ ${ }^{a}$ Institute of Biomaterials, University of Erlangen-Nuremberg, 91058 Erlangen, Germany \\ b Dpto. Química en Ciencias Farmacéuticas, Universidad Complutense, Instituto Hospital, 12 de Octubre, imas12, Madrid, Spain \\ ${ }^{c}$ CIBER-BBN, Madrid, Spain
}

\section{A R T I C L E I N F O}

\section{Keywords:}

Bioactive glasses

Ion release

Mesoporosity

Bone marrow stromal cells

Angiogenesis

\begin{abstract}
A B S T R A C T
Certain biomaterials are capable of inducing the secretion of Vascular Endothelial Growth Factor (VEGF) from cells exposed to their biochemical influence, which plays a vital role in stimulating angiogenesis. Looking for this capacity, in this study three porous glasses were synthesized and characterized. Glass compositions (in mol-\%) were: $60 \mathrm{SiO}_{2}-(36-2 \mathrm{x}) \mathrm{CaO}-4 \mathrm{P}_{2} \mathrm{O}_{5}-\mathrm{xCuO}-\mathrm{xSrO}$ with $\mathrm{x}=0,1$ or 2.5 , respectively, for $\mathrm{B} 60$, CuSr-1 or CuSr-2.5 glasses. $\mathrm{Cu}^{2+}$ and $\mathrm{Sr}^{2+}$ ions were added because of the reported biological capabilities of $\mathrm{Cu}^{2+}$ as angiogenic stimulator and $\mathrm{Sr}^{2+}$ as osteogenic stimulator. The objective of this study was to determine the concentration of the glass particles that, being out of the cytotoxic range, could increase VEGF secretion. The viability of cultivated bone marrow stromal cells (ST-2) was assessed. The samples were examined with light microscopy (LM) after the histochemical staining for haematoxylin and eosin (HE). The biological activity of glasses was evaluated in terms of the influence of the $\mathrm{Cu}^{2+}$ and $\mathrm{Sr}^{2+}$ ions on the cells. The dissolution products of CuSr-1 and CuSr- 2.5 produced the highest secretion of VEGF from ST-2 cells after $48 \mathrm{~h}$ of incubation. The combination of $\mathrm{Cu}^{2+}$ and $\mathrm{Sr}^{2+}$ lays the foundation for engineering a bioactive glass than can lead to vascularized, functional bone tissue when used in bone regeneration applications.
\end{abstract}

\section{Introduction}

Neovascularization is a critical step in bone repair and regeneration as bone is a vascularized tissue which relies on the close interaction between blood vessels and bone cells [1]. Several signaling molecules are involved in angiogenesis such as the Vascular Endothelial Growth Factor (VEGF), the basic fibroblast growth factor (bFGF), and various members of the transforming growth factor beta (TGF $\beta$ ) family. VEGF is a signaling molecule secreted by hypertrophic chondrocytes and induces angiogenesis from the perichondrium leading to the recruitment of osteoblasts, osteoclasts and haemotopoietic cells [2]. VEGF, as a single agent, stimulates osteogenesis by activating osteoblasts and angiogenesis by activating endothelial cells to support bone repair $[3,4]$.

In the last decade, studies have shown that certain compositions of bioactive glasses stimulate the production of angiogenic growth factors such as VEGF both in vitro and in vivo [5-8]. In the last years novel bioactive glasses containing mesopores, i.e. in the $2-10 \mathrm{~nm}$ range, which exhibit novel features not present in the classical melt-derived bioactive glasses, have been developed by sol-gel methods [9]. These glasses were first proposed in 1991 [10] and their ordered mesoporous variants, mesoporous bioactive glasses (MBGs), were first proposed in 2004 [11]. MBGs were further characterized by Wu and Chang [12] and previous work in the field has been reviewed by Izquierdo-Barba and Vallet-Regí [13]. MBGs exhibit high in vitro bioactivity and controllable drug delivery capability which can be exploited for various biomedical applications including cancer therapy. Compared with traditional sol-gel derived glasses, MBGs exhibit ordered arrangements of mesopores and a very narrow pore size distribution $[14,15]$ These features make MBGs more appropriate for the design of drug delivery and stimulus-responsive systems $[9,13]$. However, for their applications in

\footnotetext{
* Corresponding author.

Email address: aldo.boccaccini@ww.uni-erlangen.de (A.R. Boccaccini)
} 
bone regeneration, both families of bioactive glasses exhibit similar behavior after implantation.

On the other hand, the incorporation of therapeutic ions such as lithium, boron, copper, strontium, magnesium, zinc, silver and others in the composition of any of the three families of bioactive glasses (i.e. melt-derived glasses, sol-gel derived glasses or MBGs), has been shown to be beneficial in influencing several biological functions such as osteogenesis, angiogenesis and anti-bacterial activity [16-19]. In this sense, ions such as $\mathrm{Sr}^{2+}$ improve osteoblast differentiation by coordinating with various osteoblastic genes and they also have an effect on osteoclastic activity [19-23]. In addition, copper ions have been known for decades to stimulate angiogenesis and enhance the development of blood vessels to construct a vascularized structure [7, 16, 24-27]. In this context, the mechanisms by which cobalt ions (not investigated in this article) and copper ions stimulate angiogenesis have been described in literature $[28,29]$.

In this work, three new bioactive glasses with composition (in mol-\%) $60 \mathrm{SiO}_{2}-(36-2 \mathrm{x}) \mathrm{CaO}-4 \mathrm{P}_{2} \mathrm{O}_{5}-\mathrm{xCuO}-\mathrm{xSrO}$ with $\mathrm{x}=0,1$ or 2.5 were obtained by a wet chemistry based method. Table 1 shows the compositions of the three glasses and the codes used to identify them. For the undoped glass (free of $\mathrm{CuO}$ and $\mathrm{SrO}$ ) the code chosen was $\mathrm{B} 60$ to highlight its bioactive character and the $\mathrm{SiO}_{2}$ content $(60 \mathrm{~mol} \%)$. For the other two glasses, their respective codes were CuSr-1 and CuSr-2.5 to highlight their content in $\mathrm{CuO}$ and $\mathrm{SrO}$. There is limited previous work on Sr-Cu-containing MBGs based on the $\mathrm{SiO}_{2}-\mathrm{CaO}$ binary system, e.g. without $\mathrm{P}$ [30]. The present paper focuses on the evaluation of the secretion of VEGF from mouse stromal cells (ST-2 cells) from bone marrow when cultured in the presence of the dissolution products of bioactive glasses. The final aim of this study was to determine the concentration of the glass particles (size $<32 \mu \mathrm{m}$ ) that, being out of the cytotoxic range, could increase VEGF secretion under the mentioned in vitro conditions, highlighting the angiogenic effect of the glasses in relation to the presence of $\mathrm{Sr}^{2+}$ and $\mathrm{Cu}^{2+}$ ions.

\section{Experimental procedure}

\subsection{Glass synthesis}

Glasses were synthesized by using the evaporation-induced self-assembly (EISA) method [31]. The nonionic surfactant Pluronic ${ }^{\circledR}$ _ P123 (Sigma-Aldrich) was used as a structure-directing agent. Pluronic $₫$ is an amphiphilic triblock copolymer having the sequence poly(ethylene oxide) ${ }_{20}$-poly(propylene oxide) ${ }_{70}$-poly(ethylene oxide) 20 . During synthesis, $4.5 \mathrm{~g}$ of Pluronic ${ }^{\circledR}$ P123 was dissolved $(1 \mathrm{~h})$ in $85 \mathrm{~mL}$ of ethanol with $1.12 \mathrm{~mL}$ of $0.5 \mathrm{~N} \mathrm{HNO}_{3}$. Every $3 \mathrm{~h}$ interval other reactants were added under continuous stirring in the order: tetraethyl orthosilicate (TEOS), triethyl phosphate (TEP), calcium nitrate, cooper nitrate and strontium nitrate (all the reactants of Sigma-Aldrich), keeping the flask covered by a plastic paraffin film (Parafilm $\AA$ ) in the amounts indicated in Table 2. Following the EISA process, the sol was cast in a Petri dish for gelation, which took $35 \mathrm{~h}$. Then, gels were aged for 7 days at room temperature. The dried gels were removed as a homogeneous, transparent membrane and heated at $700{ }^{\circ} \mathrm{C}$ for $3 \mathrm{~h}$ to remove the surfactant and nitrate groups, and to stabilize the resultant porous glasses under atmospheric conditions. Obtained materials were milled and sieved to

Table 1

Composition (in mol\%) of glasses investigated in this study.

\begin{tabular}{llllll}
\hline Acronym & $\mathrm{SiO}_{2}$ & $\mathrm{CaO}$ & $\mathrm{P}_{2} \mathrm{O}_{5}$ & $\mathrm{CuO}$ & $\mathrm{SrO}$ \\
\hline $\mathrm{B} 60$ & 60 & 36 & 4 & - & - \\
$\mathrm{CuSr}-1$ & 60 & 34 & 4 & 1 & 1 \\
CuSr-2.5 & 60 & 31 & 4 & 2.5 & 2.5 \\
\hline
\end{tabular}

obtain grains of size $<32 \mu \mathrm{m}$ giving rise to $\mathrm{B} 60$, CuSr-1 and CuSr-2.5 samples.

\subsection{Glass characterization}

The mesopore structure was evaluated by transmission electron microscopy (TEM) in a JEM-2100 microscope (JEOL), operating at $200 \mathrm{kV}$, equipped with an energy dispersive X-ray (EDX; Oxford INCA) microanalysis stage. Nitrogen adsorption-desorption isotherms at $77.35 \mathrm{~K}$ used to determine the textural properties were acquired using a ASAP 2020 porosimeter (Micromeritics). Before the adsorption measurements, the samples were degassed under vacuum for $24 \mathrm{~h}$ at $120^{\circ} \mathrm{C}$. The surface area was obtained by applying the Brunauer-Emmett-Teller (BET) method. The pore size distribution was determined by the Barrett-Joyner-Halenda (BJH) method from the adsorption branch of the isotherm [32]. Magic angle- spinning (MAS) and single-pulse solid-state nuclear magnetic resonance (NMR) measurements were performed to evaluate the different silicon and phosphorus environments in the synthesized samples. The NMR spectra were recorded on an Advance 400 spectrometer (Bruker). Samples were spun at $10 \mathrm{kHz}$ for ${ }^{29} \mathrm{Si}$ and $6 \mathrm{kHz}$ for ${ }^{31} \mathrm{P}$. Spectrometer frequencies were set to 79.49 and $161.97 \mathrm{MHz}$ for ${ }^{29} \mathrm{Si}$ and ${ }^{31} \mathrm{P}$, respectively. Chemical shift values were referenced to tetramethylsilane and $\mathrm{H}_{3} \mathrm{PO}_{4}$ for ${ }^{29} \mathrm{Si}$ and ${ }^{31} \mathrm{P}$, respectively. All spectra were obtained using a proton enhanced cross polarization (CP) method, using a contact time of $1 \mathrm{~ms}$. The time periods between successive accumulations were 5 and $4 \mathrm{~s}$ for ${ }^{29} \mathrm{Si}$ and ${ }^{31} \mathrm{P}$, respectively, and the number of scans was 10.000 for all the spectra.

\subsection{Cell culture}

Cell culture experiments were performed according to the previously described procedure [33-35]. A bone marrow stromal cell line (ST-2, Deutsche Sammlung für Mikroorganismen und Zellkultur, Germany), isolated from bone marrow of BC8 mice, was used for cell culture experiments. Cells were cultured in RPMI 1640 medium (Gibco, Germany) containing $10 \mathrm{vol} \%$ FBS (Sigma-Aldrich, Germany) and 1 vol\% penicillin/streptomycin (Sigma-Aldrich).

ST-2 cells were seeded for $24 \mathrm{~h}$ at 100.000 cells $/ \mathrm{mL}$. At the same time, $0.1 \mathrm{~g}$ of the three glass powders were added to $10 \mathrm{~mL}$ culture media (without cells) and incubated separately for $24 \mathrm{~h}$ at $37^{\circ} \mathrm{C}$. After $24 \mathrm{~h}$, the supernatant was extracted and diluted into different concentrations (0; $0.01 ; 0.1 ; 1 \mathrm{wt} / \mathrm{vol})$ from all samples. The seeded ST-2 cells were washed with Phosphate Buffered Saline (PBS) and the different dilutions of supernatant from the pre-incubated granules were transferred to the ST- 2 cells for further $48 \mathrm{~h}$. In these tests, the cultured cells do not come in direct contact with the glass granules, but only with the ionic dissolution products.

A WST-8 assay was carried out to evaluate the viability of the cultivated cells, as described previously [33]. The samples were examined with light microscope (LM) after the histochemical staining using haematoxylin and eosin (HE).

\subsection{VEGF release}

The amount of released VEGF from ST-2 cells into the cell culture medium was measured by using a RayBio Human VEGF ELISA (Enzyme-Linked Immunosorbent Assay) kit. This assay, for the quantitative measurement of VEGF in cell culture supernatants, employs an antibody specific for mouse VEGF coated on a 96-well plate. The changes of color from blue to yellow are detected and the intensity of the color is measured at $450 \mathrm{~nm}$ (Phomo, Anthos Mikrosysteme GmbH, Germany). The assay procedure was performed according to the manufacturer's instructions. 
Table 2

Amount of reactants used in the glass synthesis and composition of the resultant glasses (in wt\%) determined by EDX.

\begin{tabular}{|c|c|c|c|c|c|c|c|c|c|c|}
\hline Sample & TEOS (mL) & TEP $(\mathrm{mL})$ & $\mathrm{Ca}\left(\mathrm{NO}_{3}\right)_{2} \cdot 4 \mathrm{H}_{2} \mathrm{O}(\mathrm{g})$ & $\mathrm{Cu}\left(\mathrm{NO}_{3}\right)_{2} \cdot 2.5 \mathrm{H}_{2} \mathrm{O}(\mathrm{g})$ & $\mathrm{Sr}\left(\mathrm{NO}_{3}\right)_{2}(\mathrm{~g})$ & $\mathrm{SiO}_{2} \%$ & $\mathrm{CaO} \%$ & $\mathrm{P}_{2} \mathrm{O}_{5}$ & $\mathrm{CuO} \%$ & $\mathrm{SrO} \%$ \\
\hline B60 & 7.67 & 0.79 & 4.54 & _ & - & $62 \pm 2$ & $34 \pm 1$ & $4 \pm 1$ & - & - \\
\hline CuSr-1 & 7.67 & 0.79 & 4.14 & 0.13 & 0.12 & $63 \pm 2$ & $30 \pm 3$ & $4 \pm 1$ & $0.8 \pm 0.1$ & $1.6 \pm 0.7$ \\
\hline CuSr-2.5 & 7.67 & 0.79 & 3.47 & 0.33 & 0.30 & $62 \pm 5$ & $32 \pm 5$ & $2 \pm 1$ & $2.3 \pm 0.3$ & $1.5 \pm 0.5$ \\
\hline
\end{tabular}




\subsection{Statistics}

All in vitro results are presented using the mean value and standard deviation of six replicates of each sample type. All results were normalized to $0 \mathrm{wt} / \mathrm{vol}$. ( $=100 \%$ ). The differences in analysis parameters between the different samples and the different particle concentrations investigated were evaluated by one-way analysis of variance (ANOVA). The level of statistical significance was defined at $\mathrm{p}<.05$ (Origin 8.1G, Origin Lab Corporations, USA). The significance level was set as $\mathrm{p}<.05=*, \mathrm{p}<.01=* *$ and $\mathrm{p}<.001=* * *$. For comparison of the mean values, the Tukey test was applied.

\section{Results}

\subsection{Glass characterization}

Fig. 1 shows TEM images and EDX spectra of the three synthesized glasses B60, CuSr-1 and CuSr-2.5. TEM micrographs show the absence of a mesoporosus order, although in some areas a worm-like mesopore structure can be seen. On the other hand, EDX confirms the presence of $\mathrm{Si}, \mathrm{Ca}, \mathrm{P}, \mathrm{Sr}$ and $\mathrm{Cu}$ in the glasses in analogous amounts to the nominal glass composition. The elemental weight-percentages obtained are included in Table 2. The presence of Ni detected by EDX comes from the Ni-grids used in these studies (because the Cu content in two of the investigated glasses).

Nitrogen adsorption/desorption isotherms and pore size distribution curves of B60, CuSr-1 and CuSr-2.5 are shown in Fig. 2. Inset tables display the specific surface area $\left(S_{B E T}\right)$, pore diameter $\left(D_{P}\right)$ and pore
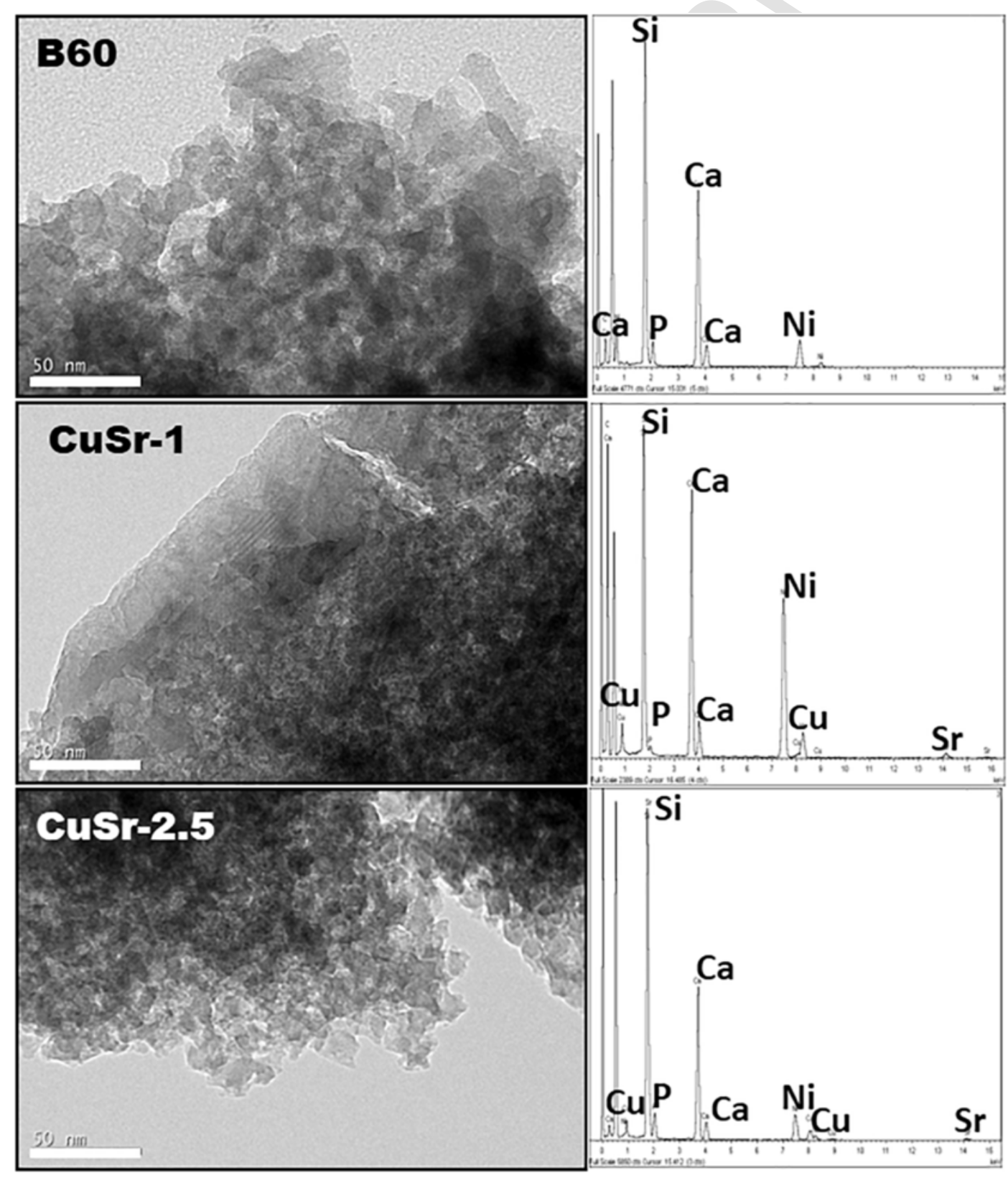

Fig. 1. TEM micrographs (left) and EDX spectra (right) of B60, CuSr-1 and CuSr-2.5 bioactive glasses. 

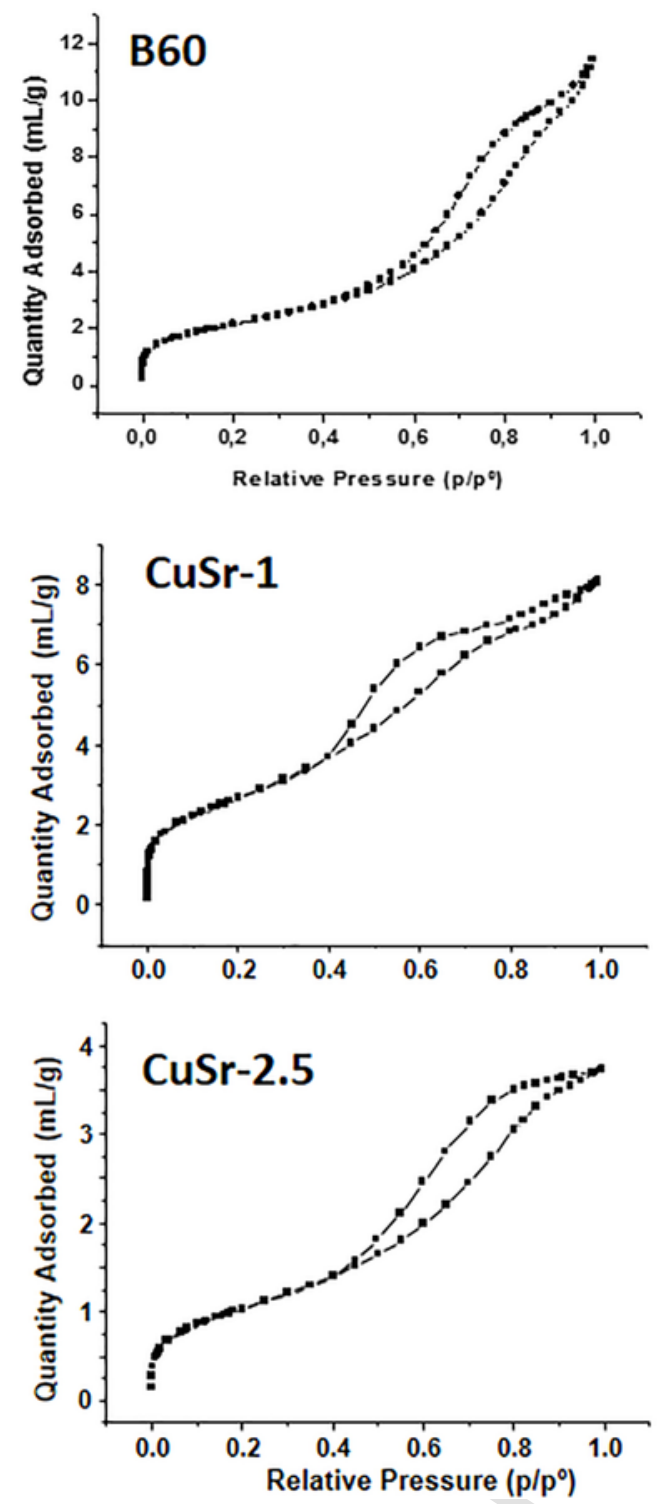
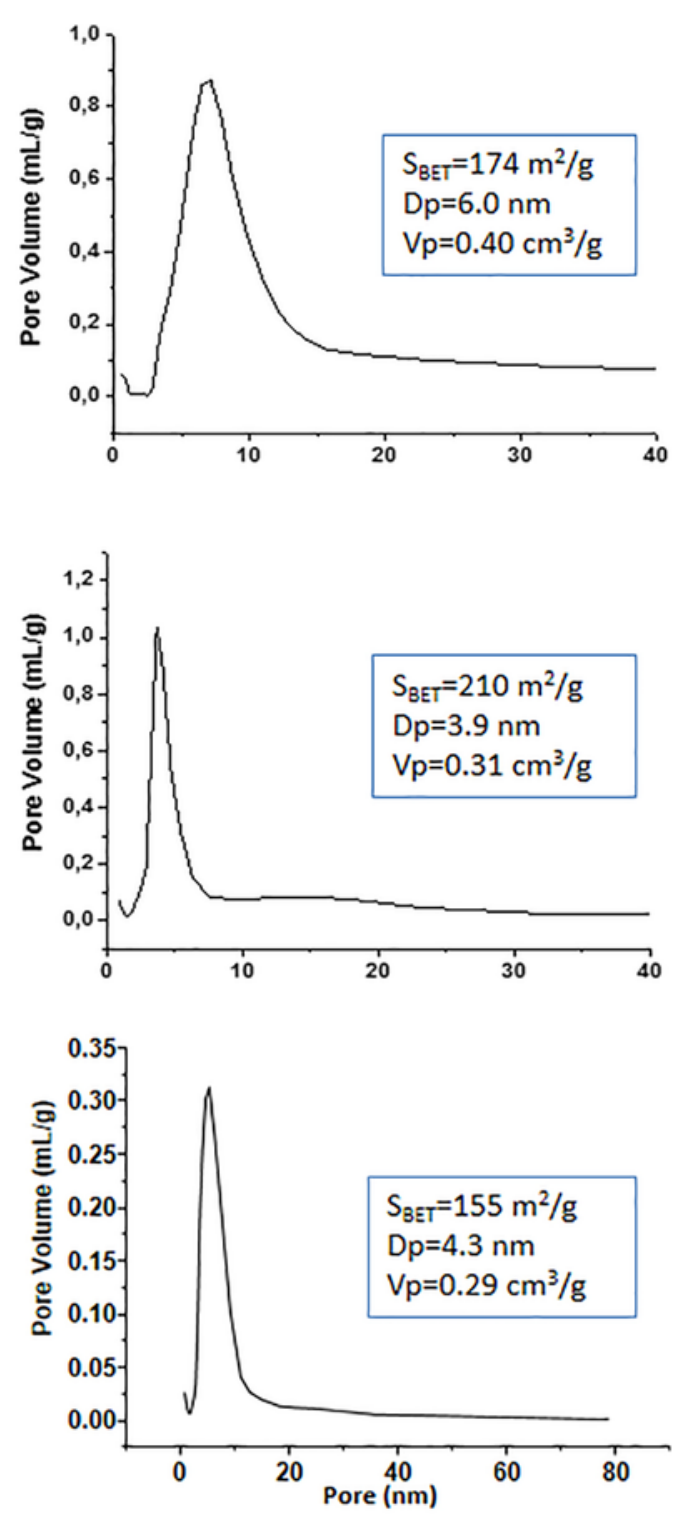

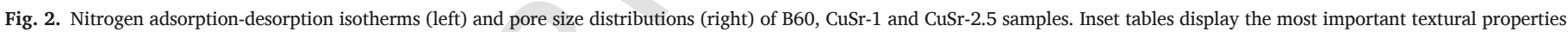
of the porous glasses: Surface area $\left(\mathrm{S}_{\mathrm{BET}}\right)$, pore diameter $(\mathrm{Dp})$ and Volume of pores $\left(\mathrm{V}_{\mathrm{P}}\right)$.

volume $\left(\mathrm{V}_{\mathrm{P}}\right)$ values for each sample. Isotherms can be identified as type IV according to the IUPAC classification, typical of mesoporous solids [36]. Moreover, the presence of $\mathrm{H} 1$ type hysteresis loops in the mesopore range indicated the existence of open ended cylindrical mesopores with narrow pore size distributions $[32,37]$. As observed, $\mathrm{S}_{\mathrm{BET}}$ values ranged between $155 \mathrm{~m}^{2} / \mathrm{g}$ (CuSr-2.5) and $210 \mathrm{~m}^{2} / \mathrm{g}(\mathrm{CuSr}-1)$ being $174 \mathrm{~m}^{2} / \mathrm{g}$ for B60. Such surface areas are of the same order of magnitude of those of traditional sol-gel derived glasses and somewhat lower than that of MBGs. On the other hand, the highest values of $D_{P}$ and $V_{P}$ were measured for $\mathrm{B} 60\left(6.0 \mathrm{~nm}\right.$ and $0.40 \mathrm{~cm}^{3} / \mathrm{g}$, respectively) whereas for CuSr-1 and CuSr-2.5 $\mathrm{D}_{\mathrm{P}}$ and $\mathrm{V}_{\mathrm{P}}$ were close to $4.0 \mathrm{~nm}$ and $0.30 \mathrm{~cm}^{3} / \mathrm{g}$.

${ }^{29} \mathrm{Si}$ solid-state MAS NMR measurements were performed to investigate the environments of the network former species at the atomic level as shown in Fig. 3. $\mathrm{Q}^{2}, \mathrm{Q}^{3}$, and $\mathrm{Q}^{4}$ represent the silicon atoms denoted as $\mathrm{Si}^{*}$ in $(\mathrm{NBO})_{2} \mathrm{Si}^{*}-(\mathrm{OSi})_{2},(\mathrm{NBO}) \mathrm{Si}^{*}-(\mathrm{OSi})_{3}$ and $\mathrm{Si} *(\mathrm{OSi})_{4}$ $(\mathrm{NBO}=$ non-bonding oxygen), respectively [38]. The chemical shifts and the deconvoluted peak areas for each sample are shown. The signals in the $-110 \mathrm{ppm}$ region come from $\mathrm{Q}^{4}$ and those at $-100 \mathrm{ppm}$ come from $\mathrm{Q}^{3}$. A resonance at approximately $-92 \mathrm{ppm}$ comes from $\mathrm{Q}^{2}$, but for CuSr-1 and CuSr-2.5 samples, the resonance decreases to $-87 \mathrm{ppm}$ [39] due to the presence of $\mathrm{Cu}^{2+}$ and $\mathrm{Sr}^{2+}$ in the network.

${ }^{29} \mathrm{Si}$-MAS-NMR spectroscopy was used to evaluate the network connectivity (NC) of porous glasses as a function of chemical composition $\left(Q^{n}\right)$ (Fig. 3). B60 sample is characterized by a high percentage of $Q^{4}$ and $\mathrm{Q}^{3}$ species and a $\mathrm{NC}$ of 3.20. The introduction of $\mathrm{CuO}$ and $\mathrm{SrO}$ causes a slight decrease of $\mathrm{NC}$ relative to $\mathrm{B} 60$ sample, increasing the percentage of $\mathrm{Q}^{2}$ in detriment of $\mathrm{Q}^{3}$. Therefore, when the concentration of $\mathrm{CuO}$ and $\mathrm{SrO}$ is increased in the glass, the $\mathrm{NC}$ decreased to 3.08 and 2.98 for CuSr-1 and CuSr-2.5 glasses, respectively. These samples exhibit a higher amount of ion modifier that disrupts the mesophase formation, leading to a depolymerized silica network [40]. This is because the amount of $\mathrm{Ca}^{2+}$ necessary to act as a compensator of charge is higher than that present in the sample because some of the $\mathrm{Ca}^{2+}$ ions are involved in the $\mathrm{Q}^{0}$ species of $\mathrm{P}$. This is indicative that the joint presence of $\mathrm{Ca}^{2+}$ and $\mathrm{PO}_{4}{ }^{3-}$, results in amorphous calcium phosphate clusters located at the pore walls surface favoring the solubility of 


\section{${ }^{29} \mathrm{Si}$ single pulse MAS}

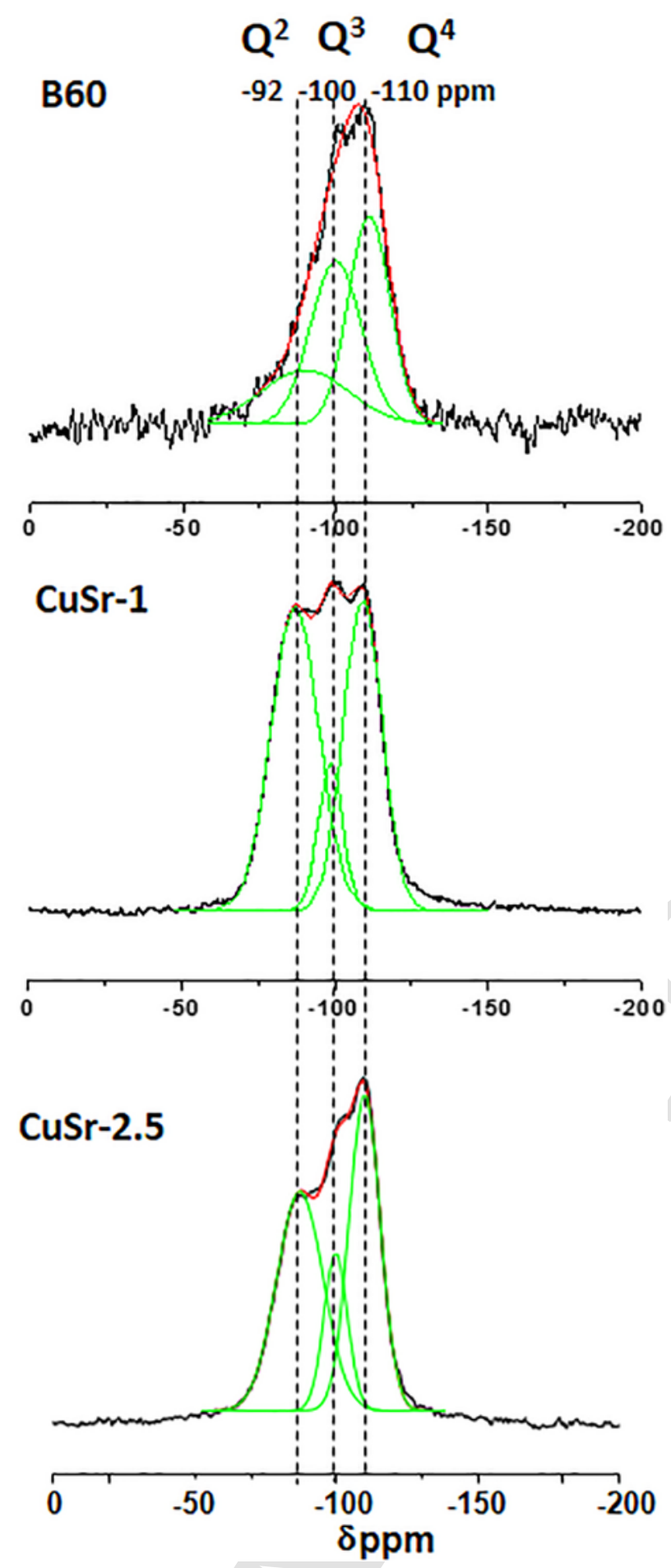

Fig. 3. Solid-state ${ }^{29} \mathrm{Si}$ single-pulse MAS-NMR spectra of B60, CuSr-1 and CuSr-2.5 of B60, CuSr-1 and CuSr-2.5 samples. The areas for the $\mathrm{Q}^{\mathrm{n}}$ units were calculated by Gaussian line-shape deconvolution and are displayed in green. (For interpretation of the references to color in this figure legend, the reader is referred to the web version of this article.)

these materials, in agreement with a previously reported model [41, 42].

In addition, ${ }^{31} \mathrm{P}$ NMR spectroscopy was used to evaluate the local environment of $\mathrm{P}$ atoms, thus elucidating the phosphate species contained in the different samples (Fig. 4). $\mathrm{Q}^{0}$ and $\mathrm{Q}^{1}$ represent phospho-

\section{${ }^{31} \mathrm{P}$ single pulse MAS}

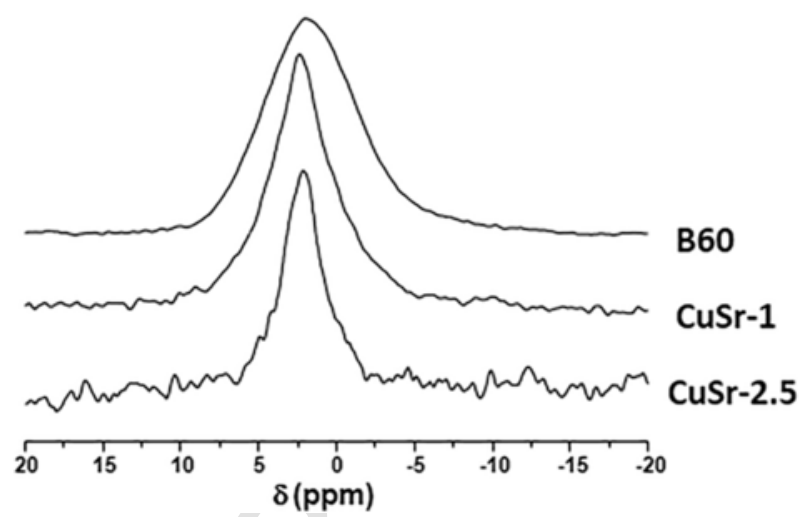

Fig. 4. Solid-state ${ }^{31} \mathrm{P}$ single-pulse MAS-NMR spectra of B60, CuSr-1 and CuSr-2.5 of B60, CuSr-1 and CuSr-2.5 samples.

rus atoms (denoted by $\mathrm{P}^{*}$ ) in the $\mathrm{PO}_{4}{ }^{3-}$ species of $\mathrm{P}^{*}-(\mathrm{NBO})_{4}$ and $(\mathrm{NBO})_{3}-\mathrm{P}^{*}-(\mathrm{OP})$, respectively. The spectra recorded by single pulse show a signal at $\sim 2 \mathrm{ppm}$ corresponding to $\mathrm{Q}^{0}$ units present in the $\mathrm{PO}_{4}$ ${ }^{3-}$ species [43]. The Full Width at Half Maximum (FWHM) for CuSr-2.5 and CuSr-1 samples are narrower than B60 indicating that the clusters are larger and more crystalline with increasing content of $\mathrm{Cu}^{2+}$ and $\mathrm{Sr}^{2+}$ ions. These results evidence that most of the $\mathrm{P}$ atoms are included as independent $\mathrm{PO}_{4}{ }^{3-}$ tetrahedra within the silica network, thus avoiding polyphosphate formation. The orthophosphates would be balanced with the divalent ions introduced in the system and the nature of these cations seems to play an important role on the characteristics of the phosphate clusters. Thus, $\mathrm{Cu}^{2+}$ and $\mathrm{Sr}^{2+}$ do not act as network formers but as network modifiers [44].

\subsection{Cell culture}

Cell viability values of ST-2 cells cultured with the supernatant of B60, CuSr-1 and CSr-2.5 glasses of different sizes and at different concentrations (0.01-1 wt/vol\%) after $48 \mathrm{~h}$ of incubation are shown in Fig. 5. Compared to the reference, B60 samples show a slight reduction in cell viability whereas the 0.1 and $1 \mathrm{wt} / \mathrm{vol} \%$ of $\mathrm{Cu}$ - and Sr- containing glasses were cytotoxic. There is a significant reduction of cell activity through the released products from the CuSr-1 and CuSr-2.5 particles. Similar results were obtained from LM images, as shown in Fig. 6. The three dilutions of $\mathrm{B} 60$ and the $0.01 \mathrm{wt} / \mathrm{vol} \%$ dilution of CuSr-1 and

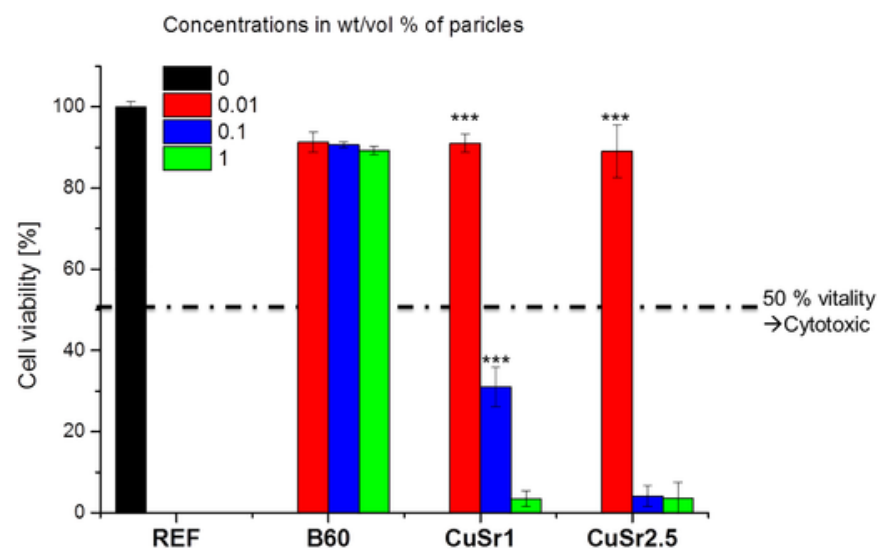

Fig. 5. Cell viability of ST-2 cells treated with the supernatant of different concentrations (0.01-1 wt/vol\%) of B60, CuSr-1 and CuSr-2.5 bioactive glasses after $48 \mathrm{~h}$ of incubation. All results were normalized to $0 \mathrm{wt} / \mathrm{vol} \%(=100 \%)$. Asterisks denote significant difference compared with $1 \mathrm{wt} / \mathrm{vol} \%$ concentration, ${ }^{* * *} \mathrm{p}<.001$ (Tukey test was used). 

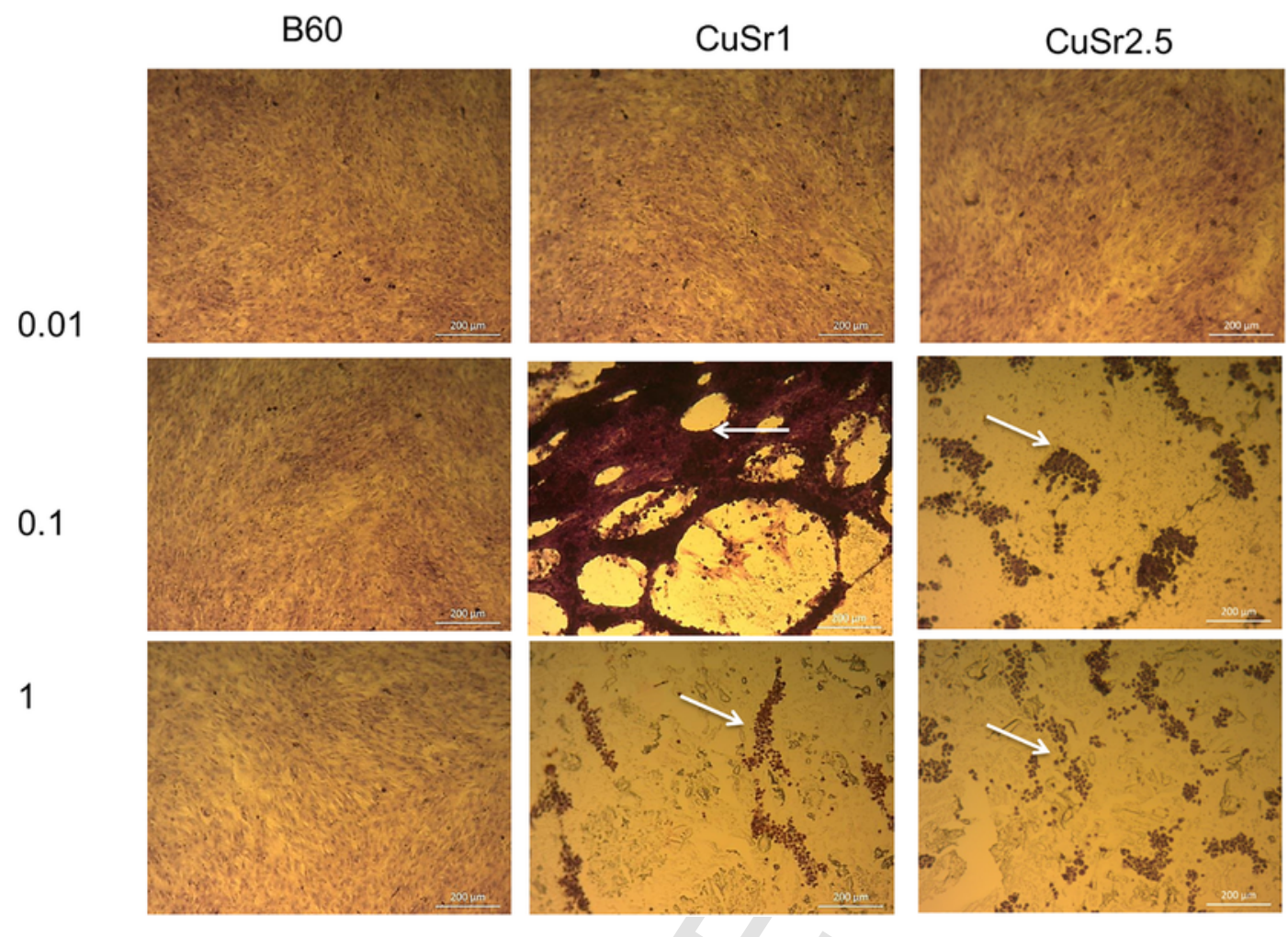

Fig. 6. Light Microscopy-images of ST-2 cells treated with the supernatant of different concentrations (0.01-1 wt/vol\%) of B60, CuSr-1 and CuSr-2.5 bioactive glasses after $48 \mathrm{~h}$ of incubation.

CuSr-2.5 have no negative influence on cell morphology, whereas higher concentrations, such 0.1 and $1 \mathrm{wt} / \mathrm{vol} \%$, were seen to disrupt the cell layer formation.

\subsection{VEGF release}

In Fig. 7, the VEGF release from ST-2 cells cultured in the supernatant of different dilutions of B60, CuSr-1 and CuSr-2.5 after $24 \mathrm{~h}$ is shown. Similar to the cell viability results and LM images, the different dilutions of $\mathrm{B} 60$ glasses showed comparable VEGF release as the reference. Interestingly, the VEGF secretion from $0.01 \mathrm{wt} / \mathrm{vol} \%$ dilution of CuSr-1 and CuSr-2.5 was significantly higher than the values of the ref-

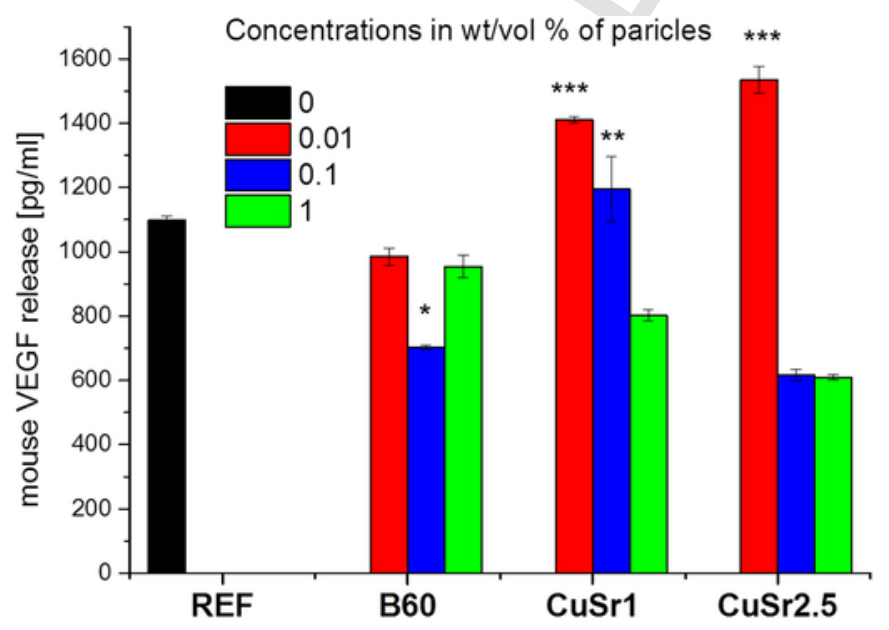

Fig. 7. Quantification of VEGF in $\mathrm{pg} / \mathrm{ml}$ released by ST-2 cells after $24 \mathrm{~h}$ of incubation with B60, CuSr-1 and CuSr-2.5 particles at different concentrations. Asterisks denote significant difference compared with $1 \mathrm{wt} / \mathrm{vol} \%$ concentration, ${ }^{* * *} \mathrm{p}<.001$ (Tukey test was used). erence and the $\mathrm{B} 60$ sample. The other two dilutions (1 and $0.1 \mathrm{wt} / \mathrm{vol} \%$ ) of CuSr-1 and CuSr-2.5 showed a decline in VEGF release.

\section{Discussion}

Two mesoporous silica glasses, CuSr-1 and CuSr-2.5, containing simultaneously $\mathrm{CuO}$ and $\mathrm{SrO}$, were prepared. The glass characterization showed that $\mathrm{Cu}^{2+}$ and $\mathrm{Sr}^{2+}$ ions behave as network modifiers. In this way, they can exert their positive biological action, which is the reason why they were included in the glass. Moreover, $\mathrm{Cu}$ and Sr-containing glasses exhibited moderate textural properties and worm-like mesopores arrangement. However, BET surface areas close to $200 \mathrm{~m}^{2} / \mathrm{g}$ and volumes of pores around $0.30 \mathrm{~cm}^{3} / \mathrm{g}$ were high enough to permit significant surface reactivity when the glasses were investigated in cell culture.

In this sense, the synthesis of porous silica-based glasses doped with biologically active ions is gaining popularity among researchers $[6,7$, $16,17,19-27,40,44-46]$. Copper is one such ions which has been known for more than two decades to play a significant role in angiogenesis [24-27, 47]. Rabbits with copper-deficiency were unable to produce an angiogenic response regardless of the type of angiogenic stimulus applied [48]. Notable amounts of cellular copper have been found in human endothelial cells when they were induced to undergo angiogenesis [47]. In recent years, copper has been incorporated into bioactive glasses in the form of scaffolds, particles and fibers for several biomedical applications [7, 19, 25-27, 49, 50]. On the other hand, strontium is considered as a promising agent in treating osteoporosis $[20,21,23,51,52]$. Moreover, Marie et al. reported the therapeutic capability of strontium in bone regeneration in vivo [53, 54] and a Sr-based drug called strontium ranelate has beneficial effects in bone healing [55]. In this study, different concentrations of $\mathrm{Cu}$ and $\mathrm{Sr}$ were added to the base $\mathrm{BG}$ composition $\mathrm{SiO}_{2}-\mathrm{CaO}-\mathrm{P}_{2} \mathrm{O}_{5}$ (Table 1) and new BG CuSr-1 and CuSr-2.5 were synthesized. The 1 and $0.1 \mathrm{wt} / \mathrm{vol} \%$ concentrations of CuSr-1 and CuSr-2.5 were found to be cytotoxic for ST-2 
cells. This could be due to the rapid release of copper and strontium ions into the solution, which ultimately increases the $\mathrm{pH}$ of the medium and kills the cells. However, the VEGF secretion was found to be the highest for the $\mathrm{Cu}$ and $\mathrm{Sr}$ containing glasses (0.01\%). Since the cells were negatively affected by the release of ions, the 1 and $0.1 \mathrm{wt} / \mathrm{vol} \%$ dilutions of CuSr-1 and CuSr-2.5 showed a decreased VEGF release. It is also important to note that the experiment was carried out in static conditions and considering the dynamics of the reactions occurring in vivo, these compositions of glasses could bring out favorable cell biology results.

As mentioned above, these elements ( $\mathrm{Cu}, \mathrm{Sr})$ have been independently incorporated in other bioceramics. For instance $\mathrm{Sr}$ has been frequently included in calcium phosphates [56-58]. In this sense Sr-substituted hydroxyapatite materials were shown to promote the proliferation, osteogenic differentiation and angiogenic factor (VEGF) expression of human osteoblast-like cells [56]. Moreover, scaffolds based on calcium phosphate bioceramic containing Sr could apparently accelerate in vivo segmental bone regeneration through stimulating VEGF secretion from osteoblasts in rabbits [57]. Lin et al. further showed that Sr and Si ions released from Sr-substituted calcium silicate bioactive ceramic scaffolds acted synergistically to stimulate the osteogenic differentiation of MSCs and angiogenesis of umbilical vein endothelial cells in vitro, promoting bone regeneration and angiogenesis in a critical-sized calvarial defect model of ovariectomized rat [58].

On the other hand, several authors demonstrated that the release of copper ions stimulates the expression of proangiogenic factors such as VEGF and transforming growth factor- $\beta$ (TGF- $\beta$ ) in wounds created in diabetic mice $[59,60]$. Subcutaneous implantation of borate bioactive glass with copper microfibers in rats significantly enhanced the growth of capillaries and small blood vessels when compared to silicate 45S5 bioactive glass microfibers [49]. The ionic dissolution product of $\mathrm{Cu}$ doped borate bioactive glass microfibers has been shown to stimulate the expression of angiogenic genes of fibroblasts in vitro and angiogenesis in full-thickness skin wounds in rodents in vivo [49]. Moreover $\mathrm{Cu}$ doped borosilicate bioactive glass scaffolds have been reported to enhance blood vessel formation and bone regeneration in vivo in rat calvarial defects [27].

Our study has shown for the first time the promising effect of simultaneously using $\mathrm{Cu}$ and $\mathrm{Sr}$, elements that, given their great angiogenic and osteogenic potential, were previously independently incorporated in different bioceramics. Further detailed analysis of the ion release from these new MBGs and the study of the long-term influence of the release kinetics on the osteogenic differentiation potential and angiogenic capability of $\mathrm{B} 60$, CuSr-1 and $\mathrm{CuSr}-2.5$ glasses will be carried out.

\section{Conclusions}

Particles $(<32 \mu \mathrm{m})$ of porous bioactive glasses with composition 60 $\mathrm{SiO}_{2}-(36-2 \mathrm{x}) \mathrm{CaO}-4 \mathrm{P}_{2} \mathrm{O}_{5}-\mathrm{xCuO}-\mathrm{xSrO}(\mathrm{x}=0,1$ or $2.5 \mathrm{~mol}-\%)$ denoted as B60, CuSr-1 and CuSr-2.5, respectively, were synthesized. The dissolution products from $\mathrm{CuSr}-1$ and $\mathrm{CuSr}-2.5$ produced high VEGF secretion from ST-2 cells after $48 \mathrm{~h}$ of incubation, highlighting their angiogenic effect in relation to the combination of an angiogenic stimulator, $\mathrm{Cu}$, and an osteogenic stimulator, Sr. These glasses showed specific surface areas between 155 and $210 \mathrm{~m}^{2} / \mathrm{g}$ and pore volumes between 0.29 and $0.40 \mathrm{~cm}^{3} / \mathrm{g}$. In addition, the $\mathrm{CuO}$ and $\mathrm{SrO}$ additions decreased the glass network connectivity in CuSr-1 and CuSr-2.5 compared to the undoped bioactive glass. These structural features enabled the effective leaching of $\mathrm{Cu}^{2+}$ and $\mathrm{Sr}^{2+}$ ions into the liquid medium. In the in vitro cell culture study, dilutions of CuSr-1 and CuSr-2.5 particles of 0.01 wt/vol\% did not affect ST-2 cells morphology leading to the highest VEGF secretion. However, for particle concentrations of $0.1 \mathrm{wt} / \mathrm{vol} \%$ or higher, cytotoxic effects were observed. The study has shown that the combination of $\mathrm{Cu}^{2+}$ and $\mathrm{Sr}^{2+}$ ions leads to bioactive glasses with angiogenic character and potential application in bone regeneration applications.

\section{Acknowledgements}

This study was supported by research grants from Instituto de Salud Carlos III (PI15/00978) project co-financed with the European Union FEDER funds, the European Research Council (ERC-2015-AdG) Advanced Grant Verdi-Proposal No.694160 and MINECO MAT2015-64831-R project.

\section{References}

[1] L. Krishnan, N.J. Willett, R.E. Guldberg, Vascularization strategies for bone regeneration, Ann. Biomed. Eng. 42 (2014) 432-444.

[2] D.I.R. Holmes, I. Zachary, The vascular endothelial growth factor (VEGF) family: angiogenic factors in health and disease, Genome Biol. 6 (2005) 209.

[3] P.J. Marie, Fibroblast growth factor signaling controlling osteoblast differentiation, Gene 316 (2003) 23-32.

[4] J. Street, M. Bao, L. de Guzman, S. Bunting, F.V. Peale, N. Ferrara, H. Steinmetz, J. Hoeffel, J.L. Cleland, A. Daugherty, N. van Bruggen, H.-P. Redmond, R.A.D. Carano, E.H. Filvaroff, Vascular endothelial growth factor stimulates bone repair by promoting angiogenesis and bone turnover, Proc. Natl. Acad. Sci. U. S. A. 99 (2002) 9656-9661.

[5] A.A. Gorustovich, J.A. Roether, A.R. Boccaccini, Effect of bioactive glasses on angiogenesis: a review of in vitro and in vivo evidences, Tissue Eng. Part B Rev. 16 (2010) 199-207.

[6] C. Wu, W. Fan, J. Chang, Y. Xiao, Mesoporous bioactive glass scaffolds for efficient delivery of vascular endothelial growth factor, J. Biomater. Appl. 28 (2012) 367-374.

[7] C. Wu, Y. Zhou, M. Xu, P. Han, L. Chen, J. Chang, Y. Xiao, Copper-containing mesoporous bioactive glass scaffolds with multifunctional properties of angiogenesis capacity, osteostimulation and antibacterial activity, Biomaterials 34 (2013) 422-433.

[8] H. Keshaw, A. Forbes, R.M. Day, Release of angiogenic growth factors from cells encapsulated in alginate beads with bioactive glass, Biomaterials 26 (2005) 4171-4179.

[9] M. Vallet-Regí, C.V. Ragel, A.J. Salinas, Glasses with medical applications, Eur. J. Inorg. Chem. (2003) 1029-1042.

[10] R. Li, A.E. Clark, L.L. Hench, An investigation of bioactive glass powders by sol-gel processing, J. Appl. Biomater. 2 (1991) 231-239.

[11] X. Yan, C. Yu, X. Zhou, J. Tang, D. Zhao, Highly ordered mesoporous bioactive glasses with superior in vitro bone forming bioactivities, Angew. Chem. Int. Ed. 43 (2004) 5980-5984.

[12] C. Wu, J. Chang, Mesoporous Bioactive Glasses: Structure Characteristics, Drug/ growth Factor Delivery and Bone Regeneration Application, Interface Focus, 2, 2012292-306.

[13] I. Izquierdo-Barba, M. Vallet-Regí, Mesoporous bioactive glasses: relevance of their porous structure compared to that of classical bioglasses, Biomed. Glasses 1 (2015) 140-150.

[14] G. Kaur, G. Pickrell, N. Sriranganathan, V. Kumar, D. Homa, Review and the state of the art: Sol-gel and melt quenched bioactive glasses for tissue engineering, J. Biomed. Mater. Res. Part B Appl. Biomater. 104 (2016) 1248-1275.

[15] H. Yun, S. Kim, Y. Hyun, S. Heo, J. Shin, Hierarchically mesoporous-macroporous bioactive glasses scaffolds for bone tissue regeneration, J. Biomed. Mater. Res. Part B Appl. Biomater. 87B (2008) 374-380.

[16] A. Hoppe, V. Mourino, A.R. Boccaccini, Therapeutic inorganic ions in bioactive glasses to enhance bone formation and beyond, Biomater. Sci. 1 (2013) 254-256.

[17] S. Sánchez-Salcedo, S. Shruti, A.J. Salinas, G. Malavasi, L. Menabue, M. Vallet-Regí, In vitro antibacterial capacity and cytocompatibility of $\mathrm{SiO}_{2}-\mathrm{CaO}-\mathrm{P}_{2} \mathrm{O}_{5}$ meso-macroporous glass scaffolds enriched with ZnO, J. Mater. Chem. B 2 (2014) 4836-4847.

[18] A.J. Salinas, M. Vallet-Regí, Glasses in bone regeneration: a multiscale issue, J. Non-Cryst. Solids 432 (2016) 9-14.

[19] M. Diba, F. Tapia, A.R. Boccaccini, L.A. Strobel, Magnesium-containing bioactive glasses for biomedical applications, Int. J. Appl. Glas. Sci. 3 (2012) 221-253.

[20] E. Gentleman, Y.C. Fredholm, G. Jell, N. Lotfibakhshaiesh, M.D. O'Donnell, R.G. Hill, M.M. Stevens, The effects of strontium-substituted bioactive glasses on osteoblasts and osteoclasts in vitro, Biomaterials 31 (2010) 3949-3956.

[21] J. Liu, S.C.F. Rawlinson, R.G. Hill, F. Fortune, Strontium-substituted bioactive glasses in vitro osteogenic and antibacterial effects, Dent. Mater. 32 (2016) $412-422$.

[22] L.A. Strobel, N. Hild, D. Mohn, W.J. Stark, A. Hoppe, U. Gbureck, R.E. Horch, U. Kneser, A.R. Boccaccini, Novel strontium-doped bioactive glass nanoparticles enhance proliferation and osteogenic differentiation of human bone marrow stromal cells, J. Nanopart. Res. 15 (2013) 1780.

[23] C. Wu, Y. Zhou, C. Lin, J. Chang, Y. Xiao, Strontium-containing mesoporous bioactive glass scaffolds with improved osteogenic/cementogenic differentiation of peri- 
odontal ligament cells for periodontal tissue engineering, Acta Biomater. 8 (2012) 3805-3815

[24] C. Gérard, L.J. Bordeleau, J. Barralet, C.J. Doillon, The stimulation of angiogenesis and collagen deposition by copper, Biomaterials 31 (2010) 824-831.

[25] H. Xie, Y.J. Kang, Role of copper in angiogenesis and its medicinal implications, Curr. Med. Chem. 16 (2009) 1304-1314.

[26] S. Zhao, L. Li, H. Wang, Y. Zhang, X. Cheng, N. Zhou, M.N. Rahaman, Z. Liu, W. Huang, C. Zhang, Wound dressings composed of copper-doped borate bioactive glass microfibers stimulate angiogenesis and heal full-thickness skin defects in a rodent model, Biomaterials 53 (2015) 379-391.

[27] H. Wang, S. Zhao, J. Zhou, Y. Shen, W. Huang, C. Zhang, M.N. Rahaman, D. Wang, Evaluation of borate bioactive glass scaffolds as a controlled delivery system for copper ions in stimulating osteogenesis and angiogenesis in bone healing, J. Mater. Chem. B 2 (2014) 8547-8557.

[28] S. Kargozar, F. Baino, S. Hamzehlou, R.G. Hill, N. Mozafari, Bioactive glasses: sprouting angiogenesis in tissue engineering, Trends Biotechnol. 36 (2018) $430-444$.

[29] M.M. Azevedo, O. Tsigkou, R. Nair, J.R. Jones, G. Jell, M.M. Stevens, Hypoxia inducible factor-stabilizing bioactive glasses for directing mesenchymal stem cell behavior, Tissue Eng Part A. 21 (2015) 382-389.

[30] A. Bari, G. Molino, S. Fiorilli, C. Vitale-Brovarone, Novel multifunctional strontium-copper co-substituted mesoporous bioactive particles, Mater. Lett. 223 (2018) $37-40$.

[31] C.J. Brinker, Y. Lu, A. Sellinger, H. Fan, Evaporation-induced self-assembly: nanostructures made easy, Adv. Mater. 11 (1999) 579-585.

[32] E.P. Barrett, L.G. Joyner, P.P. Halenda, The determination of pore volume and area distributions in porous substances. I. Computations from nitrogen isotherms, J. Am. Chem. Soc. 73 (1951) 373-380.

[33] P. Balasubramanian, L. Hupa, B. Jokic, R. Detsch, A. Grünewald, A.R. Boccaccini, Angiogenic potential of boron-containing bioactive glasses: in vitro study, J. Mater. Sci. 52 (2017) 8785-8792.

[34] P. Balasubramanian, R. Detsch, L. Esteban-Tejeda, A. Grünewald, J.S. Moya, A.R. Boccaccini, Influence of dissolution products of a novel Ca-enriched silicate bioactive glass-ceramic on VEGF release from bone marrow stromal cells, Biomed. Glasses 3 (2017) 104-110.

[35] R. Detsch, P. Stoor, A. Grünewald, J.A. Roether, N.C. Lindfors, A.R. Boccaccini, Increase in VEGF secretion from human fibroblast cells by bioactive glass S53P4 to stimulate angiogenesis in bone, J. Biomed. Mater. Res. Part A 102 (2014) 4055-4061.

[36] S.J. Gregg, K.S.W. Sing, Adsorption Surface Area and Porosity, second ed., Academic Press, New York, 1982.

[37] M. Kruk, M. Jaroniec, A. Sayari, Relations between pore structure parameters and their implications for characterization of MCM-41 using gas adsorption and x-ray diffraction, Chem. Mater. 11 (1999) 492-500.

[38] M. Vallet-Regi, A.J. Salinas, Role of the short distance order in glass reactivity, Materials 11 (2018) 415.

[39] M. Goswami, G.P. Kothiyal, L. Montagne, L. Delevoye, MAS-NMR study of lithium zinc silicate glasses and glass-ceramics with various $\mathrm{ZnO}$ content, J. Solid State Chem. 181 (2008) 269-275.

[40] S. Shruti, A.J. Salinas, G. Malavasi, G. Lusvardi, L. Menabue, G. Ferrara, P. Mustarelli, M. Vallet-Regi, Structural and in vitro study of cerium, gallium and zinc containing sol-gel bioactive glasses, J. Mater. Chem. 22 (2012) 13698-13706.

[41] H. Guo, R. Liu, J. Yang, B. Yang, X. Liang, C. Chu, A novel click lysine zwitterionic stationary phase for hydrophilic interaction liquid chromatography, J. Chromatogr. A 1223 (2012) 47-52.
[42] A. García, M. Cicuéndez, I. Izquierdo-Barba, D. Arcos, M. Vallet-Regi, Essential role of calcium phosphate heterogeneities in 2D-hexagonal and 3D-cubic $\mathrm{SiO}_{2}$-CaO- $\mathrm{P}_{2} \mathrm{O}_{5}$ mesoporous bioactive glasses, Chem. Mater. 21 (2009) 5474-5484.

[43] E. Leonova, I. Izquierdo-Barba, D. Arcos, A. López-Noriega, N. Hedin, M. Vallet-Regí, M. Edén, Multinuclear solid-state NMR studies of ordered mesoporous bioactive glasses, J. Phys. Chem. C 112 (2008) 5552-5562.

[44] A. Philippart, N. Gómez-Cerezo, D. Arcos, A.J. Salinas, E. Boccardi, M. Vallet-Regi, A.R. Boccaccini, Novel ion-doped mesoporous glasses for bone tissue engineering: Study of their structural characteristics influenced by the presence of phosphorous oxide, J. Non-Cryst. Solids 455 (2017) 90-97.

[45] S. Kaya, M. Cresswell, A.R. Boccaccini, Mesoporous silica-based bioactive glasses for antibiotic-free antibacterial applications, Mater. Sci. Eng. C 83 (2018) 99-107.

[46] S. Sanchez-Salcedo, G. Malavasi, A.J. Salinas, G. Lusvardi, L. Rigamonti, L. Menabue, M. Vallet-Regi, Highly-bioreactive silica-based mesoporous bioactive glasses enriched with gallium (III), Materials 11 (2018) 367.

[47] L. Finney, S. Vogt, T. Fukai, D. Glesne, Copper and angiogenesis: unravelling a relationship key to cancer progression, Clin. Exp. Pharmacol. Physiol. 36 (2009) 88-94.

[48] K.S. Raju, G. Alessandri, M. Ziche, P.M. Gullino, Ceruloplasmin, copper ions, and angiogenesis, J. Natl. Cancer Inst. 69 (1982) 1183-1188.

[49] Y. Lin, R.F. Brown, S.B. Jung, D.E. Day, Angiogenic effects of borate glass microfibers in a rodent model, J. Biomed. Mater. Res. Part A 102 (2014) 4491-4499.

[50] S.N. Rath, A. Brandl, A. Hiller, A. Hoppe, U. Gbureck, R.E. Horch, A.R. Boccaccini, Bioactive copper-doped glass scaffolds can stimulate endothelial cells in co-culture in combination with mesenchymal stem cells, PLoS One 9 (2014), e113319.

[51] N.A. Hamdy, Strontium ranelate improves bone microarchitecture in osteoporosis, Rheumatology (Oxford) 48 (Suppl. 4) (2009) iv9-13.

[52] P.J. Marie, Strontium as therapy for osteoporosis, Curr. Opin. Pharmacol. 5 (6 Spec. iss) (2005) 633-636.

[53] P.J. Marie, P. Ammann, G. Boivin, C. Rey, Mechanisms of Action and Therapeutic Potential of Strontium in Bone, Calcif. Tissue Int. 69 (2001) 121-129.

[54] P.J. Marie, Strontium ranelate: a physiological approach for optimizing bone formation and resorption, Bone 38 (2 Suppl. 1) (2006).

[55] Bjoern Habermann, et al., Strontium ranelate enhances callus strength more than PTH 1-34 in an osteoporotic rat model of fracture healing, Calcif. Tissue Int. 86 (2010) 82-89.

[56] K. Lin, P. Liu, L. Wei, Z. Zou, W. Zhang, Y. Qian, Y. Shen, J. Chang, Strontium substituted hydroxyapatite porous microspheres: surfactant-free hydrothermal synthesis, enhanced biological response and sustained drug release, Chem. Eng. J. 222 (2013) 49-59.

[57] Z. Gu, X. Zhang, L. Li, Q. Wang, X. Yu, T. Feng, Acceleration of segmental bone regeneration in a rabbit model by strontium-doped calcium polyphosphate scaffold through stimulating VEGF and bFGF secretion from osteoblasts, Mater. Sci. Eng. C Mater. Biol. Appl. 33 (2013) 274-281.

[58] K. Lin, L. Xia, H. Li, X. Jiang, H. Pan, Y. Xu, W.W. Lu, Z. Zhang, J. Chang, Enhanced osteoporotic bone regeneration by strontium-substituted calcium silicate bioactive ceramics, Biomaterials 34 (2013) 10028-10042.

[59] C.K. Sen, S. Khanna, M. Venojarvi, P. Trikha, E.C. Ellison, T.K. Hunt, Copper-induced vascular endothelial growth factor expression and wound healing, Am. J. Physiol. Heart Circ. Physiol. 282 (2002) 1821-1827.

[60] M. Frangoulis, P. Georgiou, C. Chrisostomidis, D. Perrea, I. Dontas, N. Kavantzas, Plast, Rat epigastric flap survival and VEGF expression after local copper application, Reconstr. Surg. 119 (2007) 837-843. 